\title{
Trace eyeblink conditioning requires the hippocampus but not autophosphorylation of $\alpha$ CaMKII in mice
}

\author{
Masuo Ohno, ${ }^{1,3}$ Wilbur Tseng, ${ }^{1}$ Alcino J. Silva, ${ }^{2}$ and John F. Disterhoft ${ }^{1}$ \\ ${ }^{1}$ Department of Physiology, Northwestern University Feinberg School of Medicine, Chicago, Illinois 60611-3008, USA; \\ ${ }^{2}$ Departments of Neurobiology, Psychiatry and Psychology, Brain Research Institute, University of California, Los Angeles, \\ Los Angeles, California 90095-1761, USA
}

\begin{abstract}
Little is known about signaling mechanisms underlying temporal associative learning. Here, we show that mice with a targeted point mutation that prevents autophosphorylation of $\alpha$ CaMKII $\left(\alpha \mathrm{CaMKII}{ }^{\mathrm{T} 286 \mathrm{~A}}\right)$ learn trace eyeblink conditioning normally. This forms a sharp contrast to the severely impaired spatial learning in the water maze and contextual fear conditioning observed in $\alpha \mathrm{CaMKII}{ }^{\mathrm{T} 286 \mathrm{~A}}$ mutants. Importantly, hippocampal lesions impaired trace eyeblink conditioning in $\alpha$ CaMKIII ${ }^{\mathrm{T} 286 \mathrm{~A}}$ mice, suggesting a potential role of hippocampal $\alpha \mathrm{CaMKII-independent}$ mechanisms. These results indicate that hippocampal signaling mechanisms that underlie temporal associative learning as assessed by trace eyeblink conditioning may differ from those of spatial and contextual learning.
\end{abstract}

The hippocampus plays a key role in the formation of episodic memory-the ability to associate and memorize events from experience set in their spatiotemporal context (Vargha-Khadem et al. 1997; Eichenbaum 2001). Signaling mechanisms underlying hippocampus-dependent spatial and contextual learning have been extensively studied (Abel and Lattal 2001; Matynia et al. 2002; Silva 2003; Tonegawa et al. 2003). For example, recent genetic approaches have demonstrated that spatial/contextual learning and long-term potentiation (LTP) are impaired in a series of calcium/calmodulin-dependent protein kinase II (CaMKII) mutants (Silva et al. 1992a,b; Mayford et al. 1996; Giese et al. 1998; Ohno et al. 2001, 2002; Bejar et al. 2002; Elgersma et al. 2002; Miller et al. 2002), providing the molecular and cellular basis of this kinase in hippocampal synaptic and behavioral memory (Lisman et al. 2002; Matynia et al. 2002; Elgersma et al. 2004). However, little is known about what mechanisms could bridge the temporal gap required to learn the association between two events and thereby form a temporal memory, an important aspect of episodic memory.

Autophosphorylation of $\alpha$ CaMKII at threonine-286 by $\mathrm{Ca}^{2+}$ influx through $\mathrm{N}$-methyl-D-aspartate (NMDA) receptors (Fukunaga et al. 1992; Ouyang et al. 1997) switches the kinase into a $\mathrm{Ca}^{2+} /$ calmodulin-independent active state (Colbran and Brown 2004; Griffith 2004). A mutation that eliminates phosphorylation of this site (T286A) blocks NMDA receptor-dependent LTP at hippocampal Schaffer collateral-CA1 pyramidal neuron synapses, a cellular mechanism underlying spatial learning and memory (Giese et al. 1998; Ohno et al. 2002). Therefore, knockin mice with a T286A mutation $\left(\alpha \mathrm{CaMKII}{ }^{\mathrm{T} 286 \mathrm{~A}}\right)$ provide us with a useful tool to examine the role of $\alpha$ CaMKII signaling in hippocampal learning. Here we applied trace eyeblink conditioning for the first time to $\alpha \mathrm{CaMKII}^{\mathrm{T} 286 \mathrm{~A}}$ mutant mice. This behavioral paradigm requires the association of events across time, since the conditioned stimuli (CS: tone) and unconditioned stimuli (US: shock) are separated by an empty trace interval. The aim of this study was to disentangle signaling mechanisms underlying tem-

\section{${ }^{3}$ Corresponding author.}

E-mail ohno@northwestern.edu; fax (312) 503-2090.

Article published online ahead of print. Article and publication date are at http://www.learnmem.org/cgi/doi/10.1101/lm.90205. poral memory formation by comparing the behavioral phenotypes of $\alpha \mathrm{CaMKII}^{\mathrm{T} 286 \mathrm{~A}}$ mice between temporal associative learning and spatial/contextual learning tasks.

Previous studies showed that eyeblink conditioning is both hippocampus- and NMDA receptor-dependent in mice if a trace interval of $250 \mathrm{msec}$ is inserted between the CS and US (Takatsuki et al. 2001; Tseng et al. 2004). Therefore, we used the trace eyeblink conditioning paradigm with a $250-\mathrm{msec}$ trace interval to test the temporal memory function of $\alpha$ CaMKII ${ }^{\mathrm{T} 286 \mathrm{~A}}$ mutants. Interestingly, during training (two sessions of 30 trials per day for $3 \mathrm{~d}), \alpha \mathrm{CaMKII}{ }^{\mathrm{T} 286 \mathrm{~A}}$ mutant mice as well as wild-type control mice showed a rapid and dramatic increase in the percentage of conditioned responses (CRs) and significant learning across sessions $\left(\alpha \mathrm{CaMKII}^{\mathrm{T} 286 \mathrm{~A}}, F_{(5,48)}=6.34, P<0.01\right.$; wild-type, $F_{(5,36)}=5.21$, $P<0.01)$, and no difference was found between $\alpha$ CaMKII $^{\mathrm{T} 286 \mathrm{~A}}$ mutants and wild-type littermates $\left(F_{(1,14)}=0.01, P>0.05\right.$; Fig. $1 \mathrm{~A})$. Importantly, pseudoconditioning, i.e., random presentations of unpaired tone and shock at the same number of times with the same temporal density, did not cause significant learning in $\alpha$ CaMKII ${ }^{\mathrm{T} 286 \mathrm{~A}}$ mutants $\left(F_{(5,36)}=0.70, P>0.05\right)$ or in wildtype mice $\left(F_{(5,42)}=0.45, P>0.05\right)$. Consequently, the traceconditioned $\alpha \mathrm{CaMKII}{ }^{\mathrm{T} 286 \mathrm{~A}}$ and wild-type mice showed significantly higher percent CRs than the respective pseudoconditioned mice during training $\left(\alpha \mathrm{CaMKII}^{\mathrm{T} 286 \mathrm{~A}}\right.$, $F_{(1,14)}=20.90, P<0.01$; wild-type, $\left.F_{(1,13)}=24.13, P<0.01\right)$, suggesting specific learning of trace eyeblink conditioning in both groups. $\alpha$ CaMKII ${ }^{\mathrm{T} 286 \mathrm{~A}}$ mice were also normal in timing characteristics of CRs during the last three sessions of training, including CR onset latency $\left(F_{(1,14)}=0.06, P>0.05\right)$, latency to the peak of the CR $\left(F_{(1,14)}=1.39, P>0.05\right)$, and duration of the CR $\left(F_{1,14}=0.20, P>0.05\right)$ (Fig. 1B).

Although our previous study showed that eyeblink conditioning with a 250-msec trace interval is sensitive to hippocampal lesions in mice (Tseng et al. 2004), we confirmed that $\alpha \mathrm{CaMKII}^{\mathrm{T} 286 \mathrm{~A}}$ mutants actually acquired this behavior in a hippocampus-dependent manner. Lesions of the hippocampus with injections of $1 \%$ ibotenic acid significantly impaired trace eyeblink conditioning in $\alpha$ CaMKII ${ }^{\mathrm{T} 286 \mathrm{~A}}$ mice compared to vehicleinjected mice $\left(F_{(1,21)}=8.85, P<0.01 ;\right.$ Fig. $\left.2 \mathrm{~A}\right)$, as in $\mathrm{C} 57 \mathrm{BL} / 6$ mice (Tseng et al. 2004). Histological examination revealed that 
A

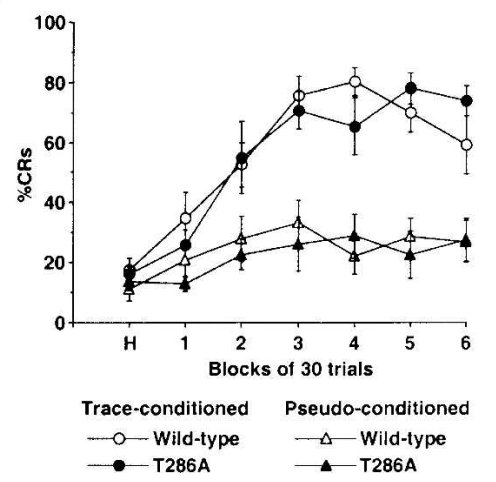

B

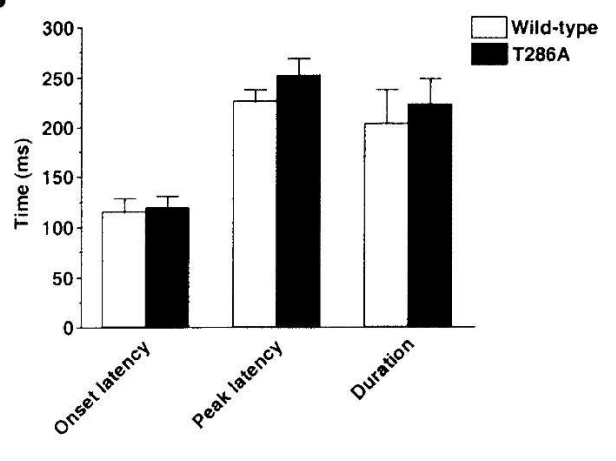

Next, we tested the $\alpha$ CaMKII $^{\mathrm{T} 286 \mathrm{~A}}$ mice with a hippocampus-dependent contextual fear conditioning paradigm, in which mice learn to associate a distinct context (CS) with an aversive foot shock (US) (Fanselow 2000; Rampon et al. 2000). Wild-type control mice exhibited a robust conditioned fear response, as measured by freezing (the absence of all but respiratory movements), when placed back in the same training context $24 \mathrm{~h}$ after two CS/US pairings (Fig. 3D). $\alpha$ CaMKII $^{\mathrm{T} 286 \mathrm{~A}}$ mutants showed significantly less freezing than wild-type mice in response to the training chamber $\left(F_{(1,14)}=68.79, P<0.01\right)$, indicating impaired contextual fear conditioning. Altogether, these results demonstrate that in contrast to normal trace eyeblink conditioning, hippocampus-dependent spatial and contextual learning is severely impaired in the $\alpha \mathrm{CaMKII}^{\mathrm{T} 286 \mathrm{~A}}$ mutants.

The $\alpha$ CaMKII signaling pathway is thought to mediate synaptic plasticity and memory formation triggered by

the mice with lesions had significant bilateral cell body loss in the hippocampus, in contrast to minor needle track and injection pressure damage in vehicle-injected control mice (Fig. 2BD). Percent CRs during trace eyeblink conditioning in the hippocampus-lesioned $\alpha \mathrm{CaMKII}^{\mathrm{T} 286 \mathrm{~A}}$ mutants were indistinguishable from those during pseudoconditioning in the intact $\alpha$ CaMKII $^{\text {T286A }}$ mice $\left(F_{(1,18)}=2.54, P>0.05\right)$, and indicated no significant learning across the training sessions $\left(F_{(5,72)}=0.72\right.$, $P>0.05)$. Taken together, these data demonstrate that $\alpha \mathrm{CaMKII}^{\mathrm{T} 286 \mathrm{~A}}$ mutants have normal temporal associative learning, as assessed by hippocampus-dependent trace eyeblink conditioning, suggesting a potential for hippocampal $\alpha$ CaMKIIindependent mechanisms underlying the formation of temporal memory.

To clarify the roles of $\alpha$ CaMKII signaling in the different types of hippocampus-dependent learning, we tested the $\alpha \mathrm{CaMKII}^{\mathrm{T} 286 \mathrm{~A}}$ mice by using Morris water maze and contextual fear conditioning paradigms (Fig. 3). In the hidden platform version of the water maze, animals learn to locate a submerged platform in a pool filled with opaque water; this spatial navigation performance is known to be hippocampus-dependent (Morris et al. 1986; Tsien et al. 1996; Cho et al. 1999). $\alpha$ CaMKII $^{\mathrm{T} 286 \mathrm{~A}} \mathrm{mu}-$ tants took more time to reach the platform than wild-type littermate mice during acquisition (three sessions of two trials per day for 4 d) $\left(F_{(1,17)}=35.99, P<0.01\right.$; Fig. 3A). After the last training trial, we gave the mice probe trials, where the platform was removed from the pool and mice were allowed to search for it for 60 sec. $\alpha \mathrm{CaMKII}^{\mathrm{T} 286 \mathrm{~A}}$ mice searched a significantly shorter time than wild-type control mice in the training quadrant (TQ) where the platform was during training $\left(F_{(1,17)}=42.77, P<0.01\right.$; Fig. 3B). Wild-type littermate mice searched significantly longer in the TQ than the other quadrants $\left(F_{(3,36)}=38.58, P<0.01\right)$ in contrast to the $\alpha$ CaMKII ${ }^{\mathrm{T} 286 \mathrm{~A}}$ mutants $\left(F_{(3,32)}=2.13, P>0.05\right)$. Using another sensitive measure of spatial learning, i.e., proximity, we confirmed that wild-type mice searched, on average, closer to the exact platform position than to the corresponding positions in the other quadrants $\left(F_{(3,36)}=24.75, P<0.01\right)$, whereas $\alpha \mathrm{CaMKII}^{\mathrm{T} 286 \mathrm{~A}}$ mutants did not $\left(F_{(3,32)}=1.68, P>0.05\right.$; Fig. $\left.3 \mathrm{C}\right)$. This proximity measure also indicated that $\alpha \mathrm{CaMKII}{ }^{\mathrm{T} 286 \mathrm{~A}}$ mice searched the training platform position less accurately than wildtype control mice did $\left(F_{(1,17)}=35.32, P<0.01\right)$.
NMDA receptor activation (Ohno et al. 2001, 2002; Matynia et al. 2002; Colbran and Brown 2004). Previous genetic and pharmacological studies showed that hippocampal NMDA signaling is crucial for spatial learning in the water maze and contextual fear conditioning (Morris et al. 1986; Tsien et al. 1996; Rampon et al. 2000). Consistent with these findings, in the present study the $\alpha \mathrm{CaMKII}^{\mathrm{T} 286 \mathrm{~A}}$ mutants were severely impaired in spatial and con-
A

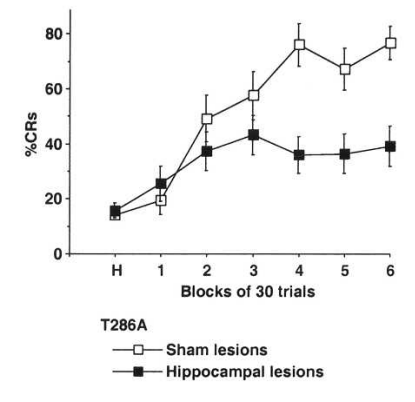

C

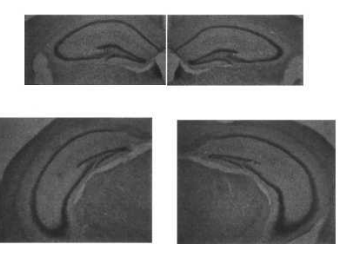

B

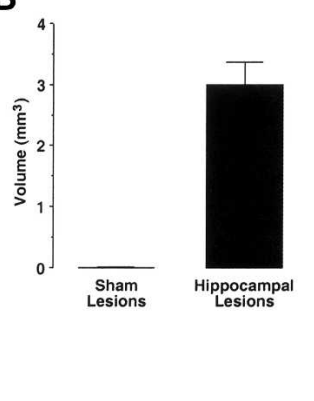

D

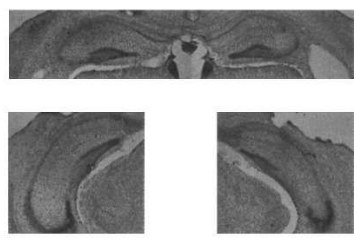

Figure 2. Hippocampal lesions impair trace eyeblink conditioning in $\alpha$ CaMKIII $^{\text {T286A }}$ mutants. $(A) \alpha$ CaMKII ${ }^{\top 286 \mathrm{~A}}$ mice received intrahippocampal injections of $1 \%$ ibotenic acid (hippocampal lesions, $n=13$ ) or vehicle (sham lesions, $n=10$ ). After one habituation session $(H)$, both groups were trained for trace eyeblink conditioning with 60 trials (two blocks of 30 trials) per day for $3 \mathrm{~d}$. The average percent CRs ( \pm SEM) are plotted across training sessions. It is clear that hippocampus-lesioned mutants show lower \% CRs than sham-lesioned control mutants during training. $(B)$ The average volume of hippocampal damage $( \pm$ SEM) is shown. One out of 14 ibotenic acid-treated mice showed damage that was confined to the hippocampus unilaterally, and thus was discarded from the data analysis. $(C, D)$ Representative histological sections from mice with a median amount of hippocampal damage from the vehicle-treated $(C)$ and ibotenic acid-treated $(D)$ groups.

\section{Learning \& Memory \\ www.learnmem.org}


Trace eyeblink conditioning in $\alpha \mathrm{CaMKII}^{\mathrm{T} 286 \mathrm{~A}}$ mutants

A
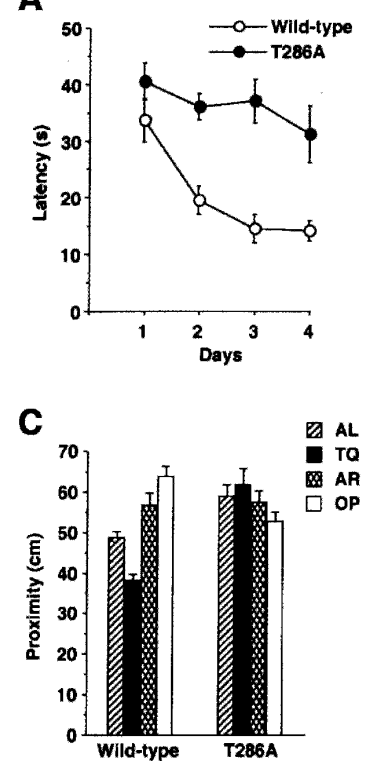

Figure 3. Spatial and contextual learning is severely impaired in $\alpha$ CaMKII ${ }^{\mathrm{T} 286 \mathrm{~A}}$ mutants. $(A) \alpha \mathrm{CaMKII}^{\mathrm{T286A}}$ mice $(n=9)$ and wild-type littermates $(n=10)$ were trained with six trials (three blocks of two trials) per day for $4 \mathrm{~d}$ in the Morris water maze. The average latency $( \pm$ SEM) to reach the hidden platform is plotted across training days. (B) Results of a probe test given after $4 \mathrm{~d}$ of training. The percentage of time ( \pm SEM) mice spent searching in each of the quadrants (AL, adjacent left; TQ, training quadrant; AR adjacent right; OP, opposite) is shown. (C) A different measure (proximity) to assess selective searching the platform position during the probe trial. Note that all of the three different measures clearly indicate spatial learning and memory deficits in $\alpha$ CaMKII ${ }^{\mathrm{T} 286 \mathrm{~A}}$ mutants. $(D) \alpha \mathrm{CaMKII}^{\mathrm{T286A}}(n=8)$ and wild-type littermate $(n=8)$ mice were trained with two CS/US pairings for contextual fear conditioning. $\alpha$ CaMKII ${ }^{\mathrm{T} 286 \mathrm{~A}}$ mutants show significantly lower levels of contextual freezing than wild-type mice when tested $24 \mathrm{~h}$ after training.

textual learning. How does the $\alpha$ CaMKII ${ }^{\mathrm{T} 286 \mathrm{~A}}$ mutation affect spatial/contextual learning? It is important to note that the hippocampal pyramidal neurons of $\alpha$ CaMKII ${ }^{\mathrm{T} 286 \mathrm{~A}}$ mutants show place fields or fire when the animal is in a particular location, but their place cells are unstable and have less spatial selectivity (Cho et al. 1998). In addition to their essential roles in spatial learning, recent evidence suggests that hippocampal place cells are also important for contextual fear learning by remapping of the training environment and allowing rapid acquisition of new associations with the context (Moita et al. 2004). It is, therefore, likely that spatial and contextual learning require similar NMDA receptor-dependent $\alpha$ CaMKII signaling mechanisms that underlie hippocampal CA1 plasticity (Ohno et al. 2002) and place cell function (McHugh et al. 1996; Cho et al. 1998).

Interestingly, our data clearly demonstrate that temporal associative learning, as assessed by hippocampus-dependent trace eyeblink conditioning, is normal in $\alpha \mathrm{CaMKII}^{\mathrm{T} 286 \mathrm{~A}}$ mutants. These results suggest that $\alpha$ CaMKII autophosphorylation or persistent activation of this kinase is not required for trace eyeblink conditioning, demonstrating a type of hippocampal learning that places less demands on $\alpha$ CaMKII mechanisms compared with spatial and contextual learning. It is important to note that CA1-specific NMDA receptor knockout mice (Huerta et al. 2000), as are mice given the intrahippocampal NMDA antagonist APV (Misane et al. 2005), are impaired in trace fear conditioning, suggesting that hippocampal NMDA signaling is crucial for the formation of memories that associate events across time. Taken together, it is reasonable to speculate that a hippocampal $\alpha$ CaMKII- independent intracellular pathway may mediate temporal memory formation after being triggered by NMDA receptor activation. However, the length of a stimulus-free trace interval between CS and US that is required to render the conditioning hippocampus-dependent is learning task-specific: $250-500 \mathrm{msec}$ and 15-30 sec for trace eyeblink and fear conditioning in mice, respectively (Huerta et al. 2000; Takehara et al. 2003; Tseng et al. 2004; Misane et al. 2005). Since the time intervals in trace fear conditioning are so much longer, we cannot exclude the possibility that the dissociation between hippocampal NMDAdependent trace fear conditioning and $\alpha$ CaMKII-independent trace eyeblink conditioning may be attributable to their trace interval differences.

In conclusion, our results provide evidence that hippocampal mechanisms underlying temporal associative learning as assessed by trace eyeblink conditioning may not involve $\alpha$ CaMKII signaling and occur differentially from spatial and contextual learning processes. Further experiments with trace eyeblink conditioning applied to genetically targeted mice will contribute to better understanding of the neural machinery responsible for temporal memory.

\section{Materials and Methods}

\section{Mice}

The generation of the $\alpha \mathrm{CaMKII}{ }^{\mathrm{T} 286 \mathrm{~A}}$ mutant mice was described previously (Giese et al. 1998). The heterozygous $\alpha$ CaMKII ${ }^{\mathrm{T} 286 \mathrm{~A}}$ population was backcrossed more than 10 generations into the C57BL/6N background from the original 129/B6 background. Homozygous $\alpha$ CaMKII ${ }^{\mathrm{T} 286 \mathrm{~A}}$ mutants and control wild-type littermates obtained by intercrosses of heterozygous mutants were used for the experiments. At 3-4 wks post-natally, the mice were weaned and genotyping was performed by PCR analysis of tail DNA. All experiments were done blind with respect to the genotype of the mice and were conducted with the approval of the Northwestern University Animal Care and Use Committee.

\section{Eyeblink conditioning}

The basic protocols for the surgery and trace eyeblink conditioning have been described (Tseng et al. 2004). Under anesthesia with Avertin, four Teflon-coated stainless steel wires were implanted; two wires were subcutaneously passed through the upper eyelid of the right eye to record EMG activity of the orbicularis oculi muscle, and the other two wires were subcutaneously passed through the periorbital region caudal to the eye to deliver the shock. One bare stainless steel wire was secured to skull screws to serve as an electrical ground. All wires were soldered to connector pins, and the connector was cemented to the skull with dental acrylic. After recovery from surgery, the mice were placed in Plexiglas cylinders in a sound-attenuated chamber and received one habituation session consisting of 30 stimulus-free trials at 30-60-sec intertrial intervals; each trial was the same duration as a conditioning trial. The next day, trace eyeblink conditioning started with the delivery of the tone CS $(250 \mathrm{msec}$, $2 \mathrm{kHz}, 85 \mathrm{~dB})$ and the shock US (100 msec). The shock intensity was adjusted daily for each mouse to elicit a head-movement response. Mice were trained by pairing the tone and shock with a 250-msec empty trace interval and received two blocks of 30 trials per day for $3 \mathrm{~d}$ (30-60-sec intertrial intervals, 3-4-h interblock intervals). The control group was given randomly unpaired tones and shocks with 15-30-sec intertrial intervals and 60 trials per session (pseudoconditioning). EMG activity during each trial was collected, rectified, and integrated using specially designed Labview routines on a computer.

\section{Lesions and histology}

The procedures for hippocampal lesions have been described (Tseng et al. 2004). Under anesthesia with Avertin, a 2- $\mu$ L Hamil- 
ton syringe with a 25-gauge needle was lowered stereotaxically $(0.25 \mathrm{~mm} / \mathrm{min})$ to the injection site in the mouse hippocampus. The coordinates [anteroposterior (AP), mediolateral (ML), dorsoventral (DV)] relative to bregma were as follows: $-2.0, \pm 1.2$, $-1.6 ;-2.5, \pm 2.2,-1.6 ;-3.0, \pm 3.2,-3.0$, and $-3.0, \pm 3.2$, -4.0 . Each injection site received $100 \mathrm{nl}$ of $1.0 \%$ ibotenic acid or vehicle (PBS; $\mathrm{pH} \mathrm{7.4)} \mathrm{at} \mathrm{a} \mathrm{rate} \mathrm{of} 10 \mathrm{nl} / \mathrm{min}$. After the injections were completed, each mouse underwent the surgical procedures for eyeblink conditioning experiments as described above.

After behavioral testing, histological examination of hippocampal lesions was performed as described (Tseng et al. 2004). After brains were fixed in $10 \%$ formalin, they were frozen, sectioned coronally $(50 \mu \mathrm{m})$ on a microtome, and stained with cresyl violet on gelatin-subbed slides. The overall volume of damage in an animal was estimated by converting the section to bitmap images using a Leica DMLB light microscope with a Canon Powershot G5 camera (5 Megapixels).

\section{Water maze}

The basic water maze protocol and apparatus have been described (Bourtchuladze et al. 1994). Before training, each mouse was handled for 2 min everyday for 7-10 d. The pool was $1.2 \mathrm{~m}$ in diameter and was made of white metal. The water was maintained at $25 \pm 1{ }^{\circ} \mathrm{C}$ and was made opaque with nontoxic white paint to hide the square, white escape platform $(10 \mathrm{~cm} \times 10 \mathrm{~cm})$. During training, the platform was submerged $(1 \mathrm{~cm})$ below the water surface and remained in the same position in the pool for a particular mouse, but groups of animals were trained with different platform positions to avoid quadrant biases. The mice received six trials per day for $4 \mathrm{~d}$ (three blocks of two trials; 1-min intertrial intervals, $1-\mathrm{h}$ interblock intervals). The mouse was placed into the water facing the wall of the pool and was allowed to search for the platform. The starting position varied among four locations in a pseudorandom manner for each trial. The trial ended either when an animal climbed onto the platform or when a maximum of $60 \mathrm{sec}$ elapsed. The mouse was placed on the platform for $60 \mathrm{sec}$ before and after each trial. At the end of training, all mice were given a probe test with the platform removed from the pool. The data collection and analysis were performed using a digital tracking device (HVS Image).

\section{Fear conditioning}

Contextual fear conditioning was tested as described (Ohno et al. 2001). During training, mice were placed in the conditioning chamber for $3 \mathrm{~min}$ and were then exposed to two foot-shocks $(0.65 \mathrm{~mA}, 1 \mathrm{sec})$ at a 1 -min interval. After the second shock delivery, mice were left in the chamber for another $1 \mathrm{~min}$. The mice were tested for contextual fear conditioning by scoring freezing behavior with automated procedures when the mice were placed back into the same conditioning chamber $24 \mathrm{~h}$ after training. The mouse's moment-to-moment position in the chamber was sampled at $4 \mathrm{~Hz}$, and the absence of all but respiratory movement through four consecutive frames $(1 \mathrm{sec})$ was scored as freezing.

\section{Statistical analysis}

A two-way ANOVA with repeated measures was used to analyze the acquisition data from the trace eyeblink conditioning and water maze experiments. Comparisons for the other measures were done by a one-way ANOVA, and post-hoc Fisher's PLSD tests were performed when appropriate.

\section{Acknowledgments}

This work was supported by NIMH grant (R01 MH067251) to M.O.

\section{References}

Abel, T. and Lattal, K.M. 2001. Molecular mechanisms of memory acquisition, consolidation and retrieval. Curr. Opin. Neurobiol. 11: 180-187.

Bejar, R., Yasuda, R., Krugers, H., Hood, K., and Mayford, M. 2002. Transgenic calmodulin-dependent protein kinase II activation:
Dose-dependent effects on synaptic plasticity, learning, and memory. J. Neurosci. 22: 5719-5726.

Bourtchuladze, R., Frenguelli, B., Blendy, J., Cioffi, D., Schutz, G., and Silva, A.J. 1994. Deficient long-term memory in mice with a targeted mutation of the cAMP-responsive element-binding protein. Cell 79: $59-68$.

Cho, Y.H., Giese, K.P., Tanila, H., Silva, A.J., and Eichenbaum, H. 1998. Abnormal hippocampal spatial representations in $\alpha \mathrm{CaMKII}^{\mathrm{T} 286 \mathrm{~A}}$ and CREB $^{\alpha \Delta-}$ mice. Science 279: 867-869.

Cho, Y.H., Friedman, E., and Silva, A.J. 1999. Ibotenate lesions of the hippocampus impair spatial learning but not contextual fear conditioning in mice. Behav. Brain Res. 98: 77-87.

Colbran, R.J. and Brown, A.M. 2004. Calcium/calmodulin-dependent protein kinase II and synaptic plasticity. Curr. Opin. Neurobiol. 14: $318-327$.

Eichenbaum, H. 2001. The hippocampus and declarative memory: Cognitive mechanisms and neural codes. Behav. Brain Res. 127: 199-207.

Elgersma, Y., Fedorov, N.B., Ikonen, S., Choi, E.S., Elgersma, M., Carvalho, O.M., Giese, K.P., and Silva, A.J. 2002. Inhibitory autophosphorylation of CaMKII controls PSD association, plasticity, and learning. Neuron 36: 493-505.

Elgersma, Y., Sweatt, J.D., and Giese, K.P. 2004. Mouse genetic approaches to investigating calcium/calmodulin-dependent protein kinase II function in plasticity and cognition. J. Neurosci. 24: $8410-8415$

Fanselow, M.S. 2000. Contextual fear, gestalt memories, and the hippocampus. Behav. Brain Res. 110: $73-81$.

Fukunaga, K., Soderling, T.R., and Miyamoto, E. 1992. Activation of $\mathrm{Ca}^{2+} /$ calmodulin-dependent protein kinase II and protein kinase C by glutamate in cultured rat hippocampal neurons. J. Biol. Chem. 267: 22527-22533.

Giese, K.P., Fedorov, N.B., Filipkowski, R.K., and Silva, A.J. 1998. Autophosphorylation at $\mathrm{Thr}^{286}$ of the $\alpha$ calcium-calmodulin kinase II in LTP and learning. Science 279: 870-873.

Griffith, L.C. 2004. Regulation of calcium/calmodulin-dependent protein kinase II activation by intramolecular and intermolecular interactions. J. Neurosci. 24: 8394-8398.

Huerta, P., Sun, L., Wilson, M., and Tonegawa, S. 2000. Formation of temporal memory requires NMDA receptors within CA1 pyramidal neurons. Neuron 25: 473-480.

Lisman, J., Schulman, H., and Cline, H. 2002. The molecular basis of CaMKII function in synaptic and behavioural memory. Nat. Rev. Neurosci. 3: 175-190.

Matynia, A., Kushner, S.A., and Silva, A.J. 2002. Genetic approaches to molecular and cellular cognition: A focus on LTP and learning and memory. Annu. Rev. Genet. 36: 687-720.

Mayford, M., Bach, M.E., Huang, Y.Y., Wang, L., Hawkins, R.D., and Kandel, E.R. 1996. Control of memory formation through regulated expression of a CaMKII transgene. Science 274: 1678-1683.

McHugh, T.J., Blum, K.I., Tsien, J.Z., Tonegawa, S., and Wilson, M.A. 1996. Impaired hippocampal representation of space in CA1-specific NMDAR1 knockout mice. Cell 87: 1339-1349.

Miller, S., Yasuda, M., Coats, J.K., Jones, Y., Martone, M.E., and Mayford, M. 2002. Disruption of dendritic translation of CaMKII $\alpha$ impairs stabilization of synaptic plasticity and memory consolidation. Neuron 36: 507-519.

Misane, I., Tovote, P., Meyer, M., Spiess, J., Ogren, S.O., and Stiedl, O. 2005. Time-dependent involvement of the dorsal hippocampus in trace fear conditioning in mice. Hippocampus (in press).

Moita, M.A., Rosis, S., Zhou, Y., LeDoux, J.E., and Blair, H.T. 2004. Putting fear in its place: Remapping of hippocampal place cells during fear conditioning. J. Neurosci. 24: 7015-7023.

Morris, R.G.M., Anderson, E., Lynch, G.S., and Baudry, M. 1986. Selective impairment of learning and blockade of long-term potentiation by an $N$-methyl-D-aspartate receptor antagonist, AP5. Nature 319: $774-776$.

Ohno, M., Frankland, P.W., Chen, A.P., Costa, R.M., and Silva, A.J. 2001. Inducible, pharmacogenetic approaches to the study of learning and memory. Nat. Neurosci. 4: 1238-1243.

Ohno, M., Frankland, P.W., and Silva, A.J. 2002. A pharmacogenetic inducible approach to the study of NMDA/ $\alpha$ CaMKII signaling in synaptic plasticity. Curr. Biol. 12: 654-656.

Ouyang, Y., Kantor, D., Harris, K.M., Schuman, E.M., and Kennedy, M.B. 1997. Visualization of the distribution of autophosphorylated calcium/calmodulin-dependent protein kinase II after tetanic stimulation in the CA1 area of the hippocampus. J. Neurosci. 17: 5416-5427.

Rampon, C., Tang, Y.P., Goodhouse, J., Shimizu, E., Kyin, M., and Tsien, J.Z. 2000. Enrichment induces structural changes and recovery from nonspatial memory deficits in CA1 NMDAR1-knockout mice. Nat. Neurosci. 3: 238-244.

\section{Learning \& Memory \\ www.learnmem.org}


Trace eyeblink conditioning in $\alpha \mathrm{CaMKII}{ }^{\mathrm{T} 286 \mathrm{~A}}$ mutants

Silva, A.J. 2003. Molecular and cellular cognitive studies of the role of synaptic plasticity in memory. J. Neurobiol. 54: 224-237.

Silva, A.J., Paylor, R., Wehner, J.M., and Tonegawa, S. 1992a. Impaired spatial learning in $\alpha$-calcium-calmodulin kinase II mutant mice. Science 257: 206-211.

Silva, A.J., Stevens, C.F., Tonegawa, S., and Wang, Y. 1992b. Deficient hippocampal long-term-potentiation in $\alpha$-calcium-calmodulin kinase II mutant mice. Science 25 7: 201-206.

Takatsuki, K., Kawahara, S., Takehara, K., Kishimoto, Y., and Kirino, Y. 2001. Effects of the noncompetitive NMDA receptor antagonist MK-801 on classical eyeblink conditioning in mice. Neuropharmacology 41: 618-628.

Takehara, K., Kawahara, S., and Kirino, Y. 2003. Time-dependent reorganization of the brain components underlying memory retention in trace eyeblink conditioning. J. Neurosci. 23: 9897-9905.

Tonegawa, S., Nakazawa, K., and Wilson, M.A. 2003. Genetic neuroscience of mammalian learning and memory. Philos. Trans. $R$. Soc. Lond. B. Biol. Sci. 358: 787-795.

Tseng, W., Guan, R., Disterhoft, J.F., and Weiss, C. 2004. Trace eyeblink conditioning is hippocampally dependent in mice. Hippocampus 14: $58-65$.

Tsien, J.Z., Huerta, P.T., and Tonegawa, S. 1996. The essential role of hippocampal CA1 NMDA receptor-dependent synaptic plasticity in spatial memory. Cell 87: 1327-1338.

Vargha-Khadem, F., Gadian, D.G., Watkins, K.E., Connelly, A., Van Paesschen, W., and Mishkin, M. 1997. Differential effects of early hippocampal pathology on episodic and semantic memory. Science 277: $376-380$.

Received December 7, 2004; accepted in revised form February 22, 2005. 


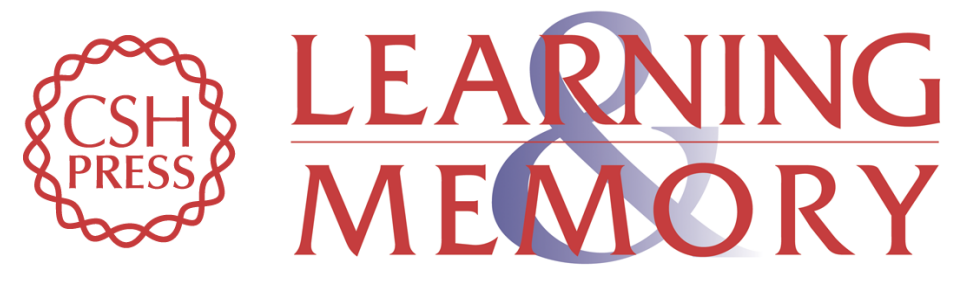

\section{Trace eyeblink conditioning requires the hippocampus but not autophosphorylation of $\alpha$ CaMKII in mice}

Masuo Ohno, Wilbur Tseng, Alcino J. Silva, et al.

Learn. Mem. 2005, 12:

Access the most recent version at doi:10.1101//m.90205

References This article cites 34 articles, 13 of which can be accessed free at:

http://learnmem.cshlp.org/content/12/3/211.full.html\#ref-list-1

License

Email Alerting Receive free email alerts when new articles cite this article - sign up in the box at the Service top right corner of the article or click here. 